\title{
La responsabilidad patrimonial de los entes instrumentales de la Administración y su transmisión a la entidad matriz
}

\author{
Ángel Ballesteros Fernández \\ Abogado \\ Secretario e Interventor-Tesorero de Administración Local
}

\begin{abstract}
Sumario: 1. LOS ENTES INSTRUMENTALES ACTÚAN COMO ÓRGANOS DE LA ENTIDAD MATRIZ. 2. RESPONSABILIDAD PATRIMONIAL DEL ENTE INSTRUMENTAL. 3. COMUNICABILIDAD ENTRE ENTE MATRIZ Y FILIAL A EFECTOS DE RESPONSABILIZAR A AQUÉL: A) Legitimación pasiva de la entidad matriz en reclamaciones de daños producidos por el ente instrumental; B) La Administración matriz puede ser demandada en cuanto titular del servicio gestionado por el ente instrumental. C) Imputación de responsabilidad a la entidad matriz por levantamiento del velo de la personalidad jurídica del ente instrumental.
\end{abstract}

\section{LOS ENTES INSTRUMENTALES ACTÚAN COMO ÓRGANOS DE LA ENTIDAD MATRIZ}

Son conocidos como entes instrumentales de la Administración aquellas personas jurídicas (en forma pública o privada) constituidas o creadas por una administración territorial, dotadas de personalidad jurídica propia, y a las que se encomienda la gestión de alguna o algunas de las competencias de titularidad del ente matriz ${ }^{1}$. En todos estos casos, la relación entre la entidad matriz y el ente personificado filial puede ser tan intensa que el carácter de persona jurídica del ente instrumental sólo juegue a efectos «ad extra», ya que, internamente, no existe mayor diferenciación entre los modos de gestión directa de servicios públicos sin personalidad y aquellos otros dotados de personalidad jurídica. E, incluso, la Jurisprudencia ha negado, esos efectos «ad extra» cuando se trata de responsabilizar al ente matriz por la actuación del ente instrumental, acudiendo a la doctrina denominada del «levantamiento del velo», que permite trascender de la vestidura de la personalidad jurídica, cuando ésta no responde a una verdadera autonomía del ente instrumental respecto de la Entidad local.

La STS de 24 de junio de 2003, destaca que

«es cierto que externamente estas sociedades mercantiles se relacionan con los usuarios bajo formas jurídicas propias del Derecho privado, pero en cambio internamente actúan casi como un órgano del ente público. En especial, desde el punto de vista de su régimen económico-financiero, forman parte del Sector público y se

\footnotetext{
${ }^{1}$ Administración instrumental. Libro homenaje a Manuel Francisco Clavero Arévalo, Madrid, 1994.
} 
REALA 300-301 (ENERO-AGOSTO, 2006)

hallan sometidas a determinadas disposiciones de la Ley General Presupuestaria, de la Ley de Contratos de las Administraciones Públicas y quedan sometidas a la fiscalización del Tribunal de Cuentas y, particularmente, es menester traer a colación el Texto articulado de la Ley especial para el Municipio de Barcelona, aprobado por Decreto de 23 de Mayo de 1960, cuyo artículo 3, apartado 1, disponía: «1. Las Entidades municipales autónomas y las Sociedades municipales, excepto las de economía mixta, estarán consideradas como órganos técnico jurídicos de gestión del Ayuntamiento, les serán aplicables los beneficios reconocidos a éste por las Leyes, especialmente disfrutarán de las exenciones y bonificaciones fiscales, prestación de créditos y demás que correspondan a las Corporaciones municipales», régimen que es fiel expresión de la consideración interna de las sociedades municipales (participadas al 100\% por el Ayuntamiento), como gestión directa de los servicios, o sea, como prestados por un órgano técnico-jurídico del mismo» ${ }^{2}$.

\section{La STC 14/1986 de 31 de enero, destacó que}

«Parece claro que, como observa la doctrina, la instrumentalidad de los entes que se personifican o que funcionan de acuerdo con el derecho privado, remiten su titularidad final a una instancia administrativa inequívocamente pública, como público es también el ámbito interno de las relaciones que conexionan dichos entes con la Administración de la que dependen, tratándose, en definitiva, de la utilización por la Administración de técnicas ofrecidas por el derecho privado, como un medio práctico de ampliar su acción social y económica. Se ha dicho también que la forma mercantil supone la introducción en el tráfico de una entidad que externamente, en sus relaciones con terceros, va a producirse bajo un régimen de derecho privado, pero internamente tal sociedad es realmente una pertenencia de la Administración, que aparece como socio exclusivo de la misma...».

\footnotetext{
${ }^{2}$ En el ámbito contractual los contratos entre la entidad matriz y la filial se consideran contratos domésticos (in home), por lo que no se sujetan a las Directrices de coordinación de los procedimientos de contratación, siempre que la entidad matriz tenga sobre la filial las mismas facultades que sobre sus órganos no dotados de personalidad. La Sentencia del Tribunal de Justicia de las Comunidades Europeas, de 11 de enero de 2005 (asunto C-26/03), da respuesta a la cuestión prejudicial planteada de «si, en el supuesto de que una entidad adjudicadora proyecte celebrar con una sociedad jurídicamente distinta de ella, en cuyo capital tiene una participación mayoritaria y sobre la que ejerce un cierto control, un contrato a título oneroso referente a servicios comprendidos en el ámbito de la Directiva 92/ 50, está siempre obligada a aplicar los procedimientos de licitación pública previstos en dicha Directiva, por el mero hecho de que una empresa privada participe, incluso en una proporción minoritaria, en el capital de esta sociedad contratista». El Tribunal sostiene que «Una autoridad pública, siendo una entidad adjudicadora, tiene la posibilidad de realizar las tareas de interés público que le corresponden con sus propios medios administrativos, técnicos y de cualquier otro tipo, sin verse obligada a recurrir a entidades externas y ajenas a sus servicios. En tal caso no existirá un contrato a título oneroso celebrado con una entidad jurídicamente distinta de la entidad adjudicadora. Así pues, no habrá lugar a aplicar las normas comunitarias en materia de contratos públicos. Con arreglo a la jurisprudencia del Tribunal de Justicia, no está excluido que puedan darse otras circunstancias en las que la licitación no sea obligatoria aunque el contratista sea una entidad jurídicamente distinta de la entidad adjudicadora. Esto sucede en el supuesto de que la autoridad pública, que es una entidad adjudicadora, ejerza sobre la entidad distinta de que se trate un control análogo al que ejerce sobre sus propios servicios y esta entidad realice la parte esencial de su actividad con la autoridad o autoridades públicas que la controlan...».
} 


\section{LA RESPONSABILIDAD PATRIMONIAL DE LOS ENTES INSTRUMENTALES DE LA ADMINISTRACIÓN}

Por ello el TC, en relación a las sociedades públicas especiales, sostiene que «si existe alguna institución cuyo encuadramiento pueda realizarse de modo más absoluto dentro de la amplia rúbrica «régimen jurídico de las Administraciones públicas», ésta es precisamente la personificación de tales administraciones para su constitución, funcionamiento y actuación en cualquiera de sus posibilidades legales...».

Conviene que retengamos, por cuanto aquí interesa, el carácter de Administraciones públicas de todos los entes instrumentales de la Administración. Porque como ha dicho MeILÁn GIL ${ }^{3}$ «no basta el dato formal de una personalidad jurídica, es preciso «levantar el velo» y comprobar cuál es el substrato real de la misma, con importantes consecuencias a la hora de la principal de las funciones de la personalidad jurídica, como es el ser centro de imputación de actos, que se evidencia en los supuestos de responsabilidad».

La LOFAGE, en el apartado XI de su Exposición de Motivos, resalta la necesidad inaplazable de racionalizar y actualizar la normativa dedicada a la tradicionalmente denominada «Administración institucional del Estado», e intenta una nueva ordenación comenzando por derogar formalmente la LEEA. Opta por una denominación genérica, que agrupa a todas las entidades de Derecho público dependientes o vinculadas a la Administración General del Estado. Y, partiendo de ese concepto general, distingue después dos modelos básicos: «Organismos Autónomos», y «Entidades públicas empresariales»:

«Los primeros — dice la Exposición de Motivos-realizan actividades fundamentalmente administrativas y se someten plenamente al derecho público; en tanto que las segundas realizan actividades de prestación o producción de bienes susceptibles de contraprestación económica y, aun cuando son regidos en general por el derecho privado, les resulta aplicable el régimen de derecho público en relación con el ejercicio de potestades públicas y con determinados aspectos de su funcionamiento».

La LOFAGE diferencia estos organismos públicos de las sociedades mercantiles estatales que se regirán íntegramente, cualquiera que sea su forma jurídica, por el ordenamiento jurídico privado, salvo en las materias que les sea de aplicación la normativa presupuestaria, contable, de control financiero y contratación. En ningún caso podrá disponer de facultades que impliquen el ejercicio de autoridad pública (D. Adicional $11^{\mathrm{a}}$ de la LOFAGE).

\section{RESPONSABILIDAD PATRIMONIAL DEL ENTE INSTRUMENTAL}

Tenemos, por tanto, entes instrumentales sometidos en todo al Derecho público o al privado o, en parte, a uno y otro. Si los entes instrumentales están

\footnotetext{
${ }^{3}$ MeILÁn GiL, J. L.: «La funcionalidad de los entes instrumentales como categoría jurídica», en Administración instrumental, libro homenaje a Manuel Francisco Clavero Arévalo, tomo II, Madrid, 1994.
} 
dotados de personalidad jurídica son centros de imputación de responsabilidad patrimonial, planteándose únicamente si esta responsabilidad será exigible ante los tribunales de lo contencioso-administrativo, por tratarse de entidades de derecho público que ejercen potestades administrativas (Organismos Autónomos y Entidades Públicas Empresariales), o ante los tribunales civiles (sociedades mercantiles públicas). Respecto de los organismos públicos (organismos autónomos y Entidades públicas empresariales) no cabe duda de que su régimen de responsabilidad será el de responsabilidad objetiva y directa, y que el orden jurisdiccional competente será el contencioso-administrativo, ya que el art. 2.2. de la LRJ y PAC dice que «las entidades de Derecho Público con personalidad jurídica propia vinculadas o dependientes de cualquiera de las Administraciones públicas tendrán asimismo la consideración de Administración pública», y el art. 144 LRJ y PAC impone el régimen de responsabilidad administrativa, que se regula en los arts. 139 y siguientes de la misma Ley, aun cuando las Administraciones públicas actúen en relaciones de Derecho privado ${ }^{4}$. El art. 3.1, párrafo segundo, del Reglamento de los Procedimientos de las Administraciones públicas en materia de responsabilidad patrimonial, señala que «en las entidades de Derecho público con personalidad jurídica propia vinculadas o dependientes de cualquiera de las Administraciones públicas, serán órganos competentes para iniciar e instruir los procedimientos los que cada entidad determine en aplicación de las normas de atribución de competencias previstas en sus normas de creación»; en cambio, la resolución del procedimiento sólo corresponderá a los órganos de la Entidad de Derecho público «cuando su norma de creación así lo determine» (según dice el art. 142.2 LRJ y PAC) ${ }^{5}$, y en los demás casos la resolución corresponderá a la Administración matriz. No es pacífica, en todo caso, la cuestión, y, así, se sostiene que las entidades públicas empresariales en cuanto se someten al Derecho privado en su actuación, ello implica que deben responder civilmente por los daños que causen a terceros, salvo en los supuestos excepcionales en que tales daños se originen en ejercicio por la entidad pública empresarial de potestades públicas ${ }^{6}$.

\footnotetext{
${ }^{4}$ Como antecedente, cabe recordar que el art. 133.2 del Reglamento de la LEF señalaba que «las Corporaciones locales y entidades institucionales quedan sujetas también a la responsabilidad que regula este Capítulo».

${ }^{5}$ La Disposición Adicional primera del Reglamento de los procedimientos de las Administraciones públicas en materia de responsabilidad patrimonial, de 1993, dispone que la responsabilidad patrimonial de las Entidades Gestoras y servicios comunes de la Seguridad Social, sean estatales o autonómicas, así como las demás entidades, servicios, y organismos del Sistema Nacional de Salud, por los daños y perjuicios causados por o con ocasión de la asistencia sanitaria deberán ser demandadas ante la jurisdiccióln contencioso-administrativa.

${ }^{6}$ Para De Vicente Domingo, R. («La responsabilidad patrimonial de los entes públicos instrumentales en la legislación y la jurisprudencia administrativa», en Nuevas perspectivas del Régimen Local. Estudios en homenaje al Profesor José $M^{a}$ Boquera Oliver, Tirant lo Blanch, Valencia, 2002), «podría defenderse que sólo cuando las actividades prestacionales cumplan una finalidad claramente pública, o sea, de servicio público, sobre todo si requieren potestades públicas, el régimen de responsabilidad será el previsto en la LRJ y PAC. En cambio, si el objeto de la entidad es la producción de bienes de interés público susceptibles de contraprestación sin necesidad de empleo de poderes el régimen sustantivo y procesal sería el civil».
} 
En cambio, en el caso de sociedades mercantiles públicas la doctrina es constante en que la responsabilidad se exigirá ante los tribunales civiles, entendiendo un sector doctrinal que la exigencia de responsabilidad se ajustará al ordenamiento propio de los servicios públicos gestionados por la sociedad, esto es, responsabilidad objetiva; mientras que otro sector doctrinal sostiene el pleno sometimiento al Derecho privado y, en consecuencia al régimen de culpa del art. 1.902 CC. GonZÁlez PEREZ ${ }^{7}$ sostiene que la empresa pública, al desarrollar la actividad propia del objeto para la que ha sido constituida, dará lugar a relaciones jurídicas, pero como se parte de la regla general de que la actividad de la empresa se regirá por las normas del Derecho común, lógico es que, en principio, el conocimiento de los litigios a que la misma dé lugar corresponda al orden jurisdiccional civil. Sin embargo, agrega el autor que citamos, no siempre rige esta regla general, y pueden surgir litigios cuyo conocimiento corresponderá al órgano jurisdiccional contencioso-administrativo, que decidirá a través del proceso administrativo. Y, así, la STS de 15 de marzo de 1973 tuvo en cuenta la naturaleza pública de una sociedad privada municipal para afirmar la competencia de los Tribunales de lo contencioso-administrativo. Para esta sentencia la naturaleza del contrato (de carácter administrativo) no queda desvirtuada por el hecho de que, en lugar de ser el propio Ayuntamiento el que de forma directa lo concertara, se verificara por la sociedad anónima municipal, constituida con esta exclusiva finalidad y por la vinculación de la sociedad a la entidad matriz ${ }^{8}$. MONTORO CHINER ${ }^{9}$ sostiene que «admitir una diferenciación de tratamiento, si los servicios se prestan bajo formas jurídicas de Derecho privado, sería equivalente a reconocer la existencia de particulares de primera o de segunda clase, pues las garantías de quienes se sintiesen lesionados por actuaciones de entidades públicas serían, hipotéticamente, mayores», por lo que preconiza la aplicación del criterio de «servicio público» como hilo conductor que permita aplicar la garantía de la responsabilidad patrimonial allí donde esté presente, materialmente, la actuación, el servicio o la función pública, conceptos éstos que no tienen por qué coincidir necesariamente y en todo caso con el de potestades administrativas. El Reglamento de Cataluña de Obras, Actividades y Servicios de los Entes locales (aprobado por Decreto 179/1995, de 13 de junio), en su artículo 218.2 dispone que «son de aplicación a la actividad de estas sociedades (de capital íntegramente público) las normas generales de responsabilidad patrimonial derivada del funcionamiento de los servicios públicos».

\footnotetext{
${ }^{7}$ GonZÁlez PÉReZ, J.: «Empresa pública y proceso», en Administración instrumental..., citado.

${ }^{8} \mathrm{El}$ art. 224 del ROF dispone que «Cuando la entidad local explote una industria o empresa como persona jurídica de derecho privado, le será aplicable las disposiciones del Código Civil sobre responsabilidad por daños y perjuicios. En tales casos asumirá respecto de los actos ejecutados por los empleados en dicha explotación la calidad de dueño patrono de la empresa a efectos de la responsabilidad que pudiera contraer por hechos ilícitos de esos agentes constitutivos de dañar a las personas, a los bienes o a los derechos de terceros».

${ }^{9}$ Montoro Chiner, M ${ }^{\mathrm{a}}$ J., y Hill Prados, M ${ }^{\mathrm{a}}$ J.: Responsabilidad patrimonial de la Administración y contrato de seguro, Atelier, Barcelona, 2002.
} 
La jurisprudencia ha negado la transmisibilidad de la responsabilidad al ente matriz precisamente por la personalidad jurídica de que está revestido el ente filial:

"Que aun admitiendo que esta empresa, con su condición de mixta, representa una fórmula de gestión directa de un servicio público, diferenciada por personificación - personificación privada - aún así, basta con que se de el requisito de la personificación para que no sea lícito confundirla con la Administración que haya contribuido a su nacimiento...».

La STS 22 de diciembre de 1999 (Sala de lo Civil) niega que la responsabilidad del Patronato se extienda al Ayuntamiento:

«Desconoce o pretende ignorar el motivo de la actuación y cometido de un organismo autónomo municipal. Cierto que el Patronato presenta una subordinación y dependencia funcional al Ayuntamiento, pero ostenta personalidad propia y cometidos determinados, incumbiéndole la gestión, promoción, administración y regulación de las instalaciones deportivas del municipio. Téngase en cuenta que la propiedad de tales recintos por parte del Ayuntamiento no es la propiedad de un bien cualquiera, sino una titularidad de bienes de uso público y con finalidad pública y para la administración, gestión, explotación y ejercicio de las facultades dominicales en bienes de esta clase se atribuyen a un ente público, con personalidad independiente del Ayuntamiento, Patronato Deportivo Municipal de Toledo. Nunca las obligaciones de seguridad y vigilancia de los recintos pueden imputarse al Ayuntamiento, pues no es la mera titularidad de bienes de uso y servicio público la generante de responsabilidades, cuando existe un ente público municipal ad hoc, con personalidad propia, diferente del Ayuntamiento, a quien incumben las obligaciones del propietario en esta clase de recintos. Pero el absurdo de la pretensión del recurrente se patentiza en que si se aceptara la responsabilidad del Excmo. Ayuntamiento de Toledo, lo que se dice tan solo a meros efectos discursivos, la responsabilidad por mal funcionamiento de servicios públicos, especialmente en daños producidos por pirotecnia y cohetes en festejos municipales y otros casos semejantes, desencadenaría la competencia de la jurisdicción contencioso-administrativa y no de esta jurisdicción civil».

\section{COMUNICABILIDAD ENTRE ENTE MATRIZ Y FILIAL A EFECTOS DE RESPONSABILIZAR A AQUÉL}

Pero fuera de estos casos excepcionales, lo cierto es que la jurisprudencia viene admitiendo que la Administración matriz pueda ser, también, responsable, directa o subsidiaria, por los daños causados a terceros por sus entes instrumentales ${ }^{10}$. El ciudadano que se relaciona con la Administración y sufre una

${ }^{10}$ Vicente Domingo, R.: «La responsabilidad patrimonial de los entes públicos instrumentales en la legislación y jurisprudencia administrativas», en Nuevas perspectivas del Régimen local. Estudios en 
LA RESPONSABILIDAD PATRIMONIAL DE LOS ENTES INSTRUMENTALES DE LA ADMINISTRACIÓN

lesión, no puede ver desatendida su petición indemnizatoria porque el daño haya sido causado por un ente instrumental de aquella. Para transmitir la responsabilidad a la Administración matriz, la jurisprudencia ha acudido a considerar bien planteada la relación jurídico-procesal si se demanda o comparece en el proceso la Administración matriz y no la filial; o estima la solidaridad de responsabilidad de la matriz y filial por ser aquélla la titular del servicio cuya gestión se encomienda a ésta; o bien, por último, acude a levantar el velo para negar virtualidad a la vestidura de la personalidad jurídica.

\section{A) Legitimación pasiva de la entidad matriz en reclamaciones de daños producidos por el ente instrumental}

Tenemos, en primer lugar, una serie de sentencias dictadas en defensa del perjudicado. Así, la STS de 4 de junio de 1992, ante reclamación al Ayuntamiento por fallecimiento de persona en piscina municipal gestionada por el Instituto Municipal de Deportes (dotado de personalidad jurídica) rechaza la excepción de falta de legitimación pasiva

«...porque es cierto que según nuestro ordenamiento jurídico positivo y según las concepciones teóricas del Derecho administrativo el Ayuntamiento tiene potestad suficiente para crear fundaciones públicas del servicio, análogas a los Organismos Autónomos estatales, con personalidad y patrimonio propios. Sin embargo es de tener en cuenta la corriente jurisprudencial mantenida por esta Sala en Sentencias recientes en el sentido de que la personificación como instrumento de la potestad organizatoria de la Administración no puede utilizarse por los entes públicos para eludir el cumplimiento de sus obligaciones y derechos que consagra el ordenamiento jurídico. Esta doctrina, plenamente aplicable al caso de autos, es precisamente la que mantiene la Sentencia apelada que en consecuencia no debe revocarse en este extremo. Pero además de ello del examen del conjunto de las actuaciones se desprende que el Ayuntamiento, como antes se ha dicho, guardó silencio ante la reclamación en vía administrativa, ignorando el deber de la Administración de dictar una resolución expresa, práctica o corruptela que, aunque sea común, constituye una infracción del ordenamiento jurídico de tanta más trascendencia cuanto se refiere al fallecimiento de una persona en el que se plantea el tema de la causalidad entre el mismo y el funcionamiento de un servicio municipal. Sólo después en vía procesal se han alegado la falta de reclamación previa y de legitimación ignorando un hecho palmario. Pues si el Ayuntamiento hubiese respondido a la reclamación indicando la vía procedimental adecuada y la organización a que debía dirigirse el reclamante, todo ello con la debida diligencia, no se hubiera planteado el tema en los términos procesales en que llegó a conocimiento del Tribunal de instancia, términos que se reproducen en el presente recurso de apelación. Por tanto el Ayuntamiento

homenaje al Profesor José $M^{a}$ Boquera Oliver, Valencia, 2002. DAVID BLANQUER: «La responsabilidad patrimonial de la Administración Local», en El Derecho local en la doctrina del Consejo de Estado, Madrid, 2002. 
debe soportar procesalmente las consecuencias de su infracción del ordenamiento jurídico al guardar silencio. Pues debe entenderse que el principio o criterio de soportar las consecuencias de las normas o actos propios se extiende también a las consecuencias de una actuación omisiva por silencio contraria al ordenamiento. En consecuencia es obligado rechazar la alegación de falta de legitimación pasiva y entrar en el estudio del fondo del asunto».

Idéntica doctrina en la STS de 31 de julio de 1992, en el que la pretensión procesal se dirigió contra acto desestimatorio presunto del Patronato local de la vivienda, que, sin embargo no se personó en el proceso; pero para el Tribunal es válida la legitimación pasiva del Ayuntamiento dado que la representación del Patronato «por identidad de sus órganos con los del Ayuntamiento, sí personado, y en función de que la pretensión tiene por objeto el cumplimiento de una obligación referida a un servicio municipal, no puede rechazarse», lo que lleva a estimar que el Patronato ha sido representado por el Ayuntamiento.

Del mismo modo, la STS (Sala de lo Civil) de 28 de mayo de 1984 entiende que existe comunicación entre el Ayuntamiento y la sociedad mercantil gestora del servicio municipal de aguas, porque:

"También en el ámbito del Derecho administrativo, cuando se habla de los entes públicos o de gestión a los que se reviste de una forma jurídica perteneciente al Derecho privado (sociedades anónimas, por ejemplo) no se hace sino utilizar una técnica ofrecida por ese Derecho de modo instrumental, del uso de un procedimiento en el que la sociedad aparece como una simple forma para encubrir la creación de un ente filial puro y simple, externamente regida por el Derecho privado, pero en realidad -internamente - de la pertenencia de la Administración... circunstancia más que suficiente para no considerar tercero extraño al Ayuntamiento con respecto a la sociedad municipal demandada y, consecuentemente, bastante para llegar a la conclusión que la interpelación hecha al Municipio vale para la sociedad como órgano integrante de ésta...».

Doctrina reiterada en la STS de 23 de febrero de 1995 para la que

«Finalmente hemos de referirnos a la tesis sostenida por el Ayuntamiento de San Sebastián de que el organizador de las fiestas de la Semana Grande, entre cuyos actos se incluía la sesión de fuegos artificiales en la que se produjo el resultado lesivo, fue el Centro de Atracción y Turismo, organismo con personalidad jurídica propia separado del Ayuntamiento. A este respecto ha de señalarse que la citada Administración demandada, tal y como ya se dice en sentencia de esta Sala de 18 de octubre de 1993, contrariamente a lo dispuesto concordadamente por los arts. 94.3 LPA 1958 y 38.2 LJCA, guardó silencio respecto de la reclamación formulada en vía administrativa y pese a ello no se recata en alegar que el organizador fue la Fundación Pública del Servicio Municipal Centro de Atracción y Turismo de San Sebastián, en la que la propia Administración Municipal demandada ostenta una posición preponderante, como lo demuestra el hecho de que no sólo crea la Funda- 
LA RESPONSABILIDAD PATRIMONIAL DE LOS ENTES INSTRUMENTALES DE LA ADMINISTRACIÓN

ción, sino que la dota de su patrimonio, contribuye a su financiación mediante aportaciones establecidas en el presupuesto ordinario municipal, se integra en su junta rectora por la presencia en la misma del Alcalde y ocho Concejales, ostentando el primero igualmente la presidencia de la Fundación, así como mediante la integración del Secretario e Interventor Municipales que a su vez desempeñan la condición de Secretario e Interventor de la Fundación Pública Municipal. No es legítimo, afirma la sentencia citada, dar la callada por respuesta para reservar la alegación de falta de legitimación pasiva a la vía jurisdiccional, de manera que el silencio administrativo sólo puede interpretarse como desestimación de la pretensión de fondo formulada en su día en relación con los perjuicios causados por la explosión ocurrida durante la sesión de fuegos artificiales, lo que obliga a desestimar la alegación que se formula por el Ayuntamiento. Cuestión íntimamente relacionada con la que acabamos de exponer es la supuesta responsabilidad del tercero que contrató con la Administración demandada y la naturaleza de la responsabilidad de los demandados como mancomunada o solidaria. Es doctrina unánime, desde la sentencia de 5 de noviembre de 1974, la aceptación de un vínculo de solidaridad entre los distintos responsables del perjuicio causado, incluso en los supuestos en que uno de los hipotéticos coautores sea un tercero ajeno a la Administración, como único medio para dar satisfacción a las exigencias propias del principio, básico en la materia, de la garantía de la víctima, que, de otro modo, correría el riesgo de quedar burlado, razón por la que no existe inconveniente para que se ejercite la acción sólo contra la Administración, sin perjuicio de que ésta pueda repetir contra los terceros, de tal manera que la vis atractiva del proceso civil sólo se produce cuando se ejercita acumulativamente la acción de responsabilidad contra la Administración y los terceros intervinientes, pero sin que esto, como queda dicho, resulte necesario por las razones antes dichas».

Y lo mismo en la STS de 22 de febrero de 1995, que reconoce que «aunque los contratos fueron otorgados por el Patronato Municipal de Cultura, que dispone de personalidad jurídica propia, debe estimarse en este caso que el Ayuntamiento puede ser también demandado en los actuales autos, pues la personalidad del Patronato es meramente operativa e instrumental...En tales circunstancias, el aceptar su falta de legitimación podría comportar una mayor dificultad en el momento de ejecutar la sentencia».

Y la STS de 22 de septiembre de 1995 que admite el emplazamiento del Ayuntamiento como demandado a pesar de que el contrato había sido celebrado por un organismo autónomo del mismo, y ello porque de los datos del expediente «comportan que la personalidad y capacidad de «Fundación Pública Teatro Municipal Miguel de Cervantes» son sólo operativas o instrumentales, suponiendo nada más que la «autonomía funcional» a que se refiere el art. I de los estatutos, realizada a través de una Gerencia de libre designación. Y ello no es suficiente para relevar al Ayuntamiento de responsabilidad, aunque sólo sea subsidiaria, en las obligaciones contraídas por el Teatro para cumplimiento de fines municipales». 
La STS de 18 de febrero de 1998 se refiere a un supuesto de responsabilidad patrimonial en principio imputable a una Junta de Puertos. Esta no fue demandada, pero sí compareció la Administración del Estado. El Abogado del Estado planteó la falta de legitimación pasiva y el litisconsorcio pasivo necesario. La Sentencia recuerda que

«Como reconoce la jurisprudencia, no existe litisconsorcio pasivo necesario entre los corresponsables solidarios y sólo nace cuando las partes están ligadas por idéntico vínculo material, como reconocen las SsTS de 14 de mayo de 1994 y de 30 de abril de1996, habiendo señalado tal criterio la jurisprudencia civil y la contencioso-administrativa en los supuestos de corresponsabilidad administrativa, sin que la falta de emplazamiento en la vía administrativa previa y en la jurisdiccional de la Junta de Obras del Puerto, suponga la estimación de las excepciones procesales señaladas, pues habiendo comparecido en las actuaciones la Abogacía del Estado, asume la representación de la Administración en su integridad, sin que a lo largo de las actuaciones del expediente administrativo ni en la vía jurisdiccional se haya efectuado una protesta formal sobre dicha no comparecencia, máxime cuando se ha producido, en todo momento, un consentimiento a la constitución de la relación jurídica procesal en la forma establecida, por lo que ni concurre la excepción de falta de legitimación pasiva, ni la excepción de litisconsorcio pasivo necesario, procediendo el examen del fondo del asunto».

\section{B) La Administración matriz puede ser demandada en cuanto titular del servicio gestionado por el ente instrumental}

La STS de 25 de febrero de 1998 acude a imputar la responsabilidad a la Administración en cuanto titular del servicio:

«En el caso examinado, la reclamación efectuada por los perjudicados no fue objeto de resolución expresa por parte de la Administración, pero ello no excluye el carácter estrictamente administrativo de la cuestión planteada, que afecta a la organización de un servicio y a su gestión, cuyo directo control sigue correspondiendo a quien ostenta la titularidad del servicio, por lo que no son los Tribunales $\mathrm{Ci}$ viles, como indican las partes recurrentes en apelación, los órganos jurisdiccionales competentes para conocer de los conflictos que pudieran surgir, sino que al tratarse de una cuestión en que la Administración ha de actuar en el ámbito de sus competencias, no se trata de una relación estricta de carácter contractual entre el concesionario y usuario, sino de una relación que afecta a la prestación del servicio público. A este respecto, independientemente de que el usuario pueda reclamar ante la Administración, solicitando el pronto restablecimiento del servicio con las debidas condiciones y que el ejercicio de una acción pueda suscitarse en el ámbito de una estricta relación concesionario-usuario ante el Juez Civil, en el caso de los daños causados que deriven de accidentes imputables a la empresa concesionaria, por mal estado de las instalaciones, o por defectuosa prestación del servicio, corresponde a los Tribunales del orden jurisdiccional contencioso-administrativo pronunciar- 
se sobre la responsabilidad de cualquier reclamación, lo que no evita el acudir a la vía civil para aspectos relativos a la estricta relación derivada de la llamada póliza de abono. En la cuestión examinada, la sentencia impugnada fundamenta la competencia de la jurisdicción contencioso-administrativa en base a los criterios manifestados por la precedente Sentencia de esta Sala de 9 mayo 1989, pero consideramos competente, en la cuestión examinada, a la jurisdicción contencioso-administrativa por los siguientes razonamientos:

a) La relación jurídica examinada es pública y administrativa, porque la empresa suministradora actuaba, en todo caso, ejerciendo poderes propios, correspondiendo a la Administración las facultades de vigilancia e inspección de las instalaciones o suspensión del suministro cuando se incurriese en faltas sancionables a la empresa concesionaria.

b) Al tratarse de una gestión de un servicio público del que es titular la Administración, se ha producido un conflicto que ha de ser resuelto por la jurisdicción contencioso-administrativa, a la que se reserva el conocimiento y solución del mismo, con el fin de controlar las condiciones en que se produce la prestación del servicio público, pues la técnica organizativa en la gestión de los servicios públicos, cuya dirección y control corresponde a la Administración, permite señalar que son los Tribunales de dicho orden jurisdiccional contencioso-administrativo los que por imperativo del artículo 106 de la Constitución, asumen su control.

c) El artículo 123 de la Ley de Expropiación Forzosa, establece el procedimiento de reclamación de responsabilidad por los perjuicios causados en desarrollo del servicio, siendo así que todas las peticiones de responsabilidad deben dirigirse a la Administración y es la jurisdicción contenciosa la competente para conocer de las decisiones de la Administración sobre la procedencia de la indemnización y sobre el sujeto imputable.

d) El anterior criterio se completa con la consideración fundamental de que la finalidad del surgimiento del instituto de la responsabilidad de la Administración, permite constatar que el título de imputación, aparte de otros que lo complementan, lo es el de la integración del servicio público en la organización administrativa, de forma que sólo cuando el agente dañoso aparezca obrando dentro de la propia estructura organizativa administrativa, podrá ser posible atribuir a aquélla el resultado dañoso y en consecuencia, hay que considerar como idea rectora en esta materia la de que en toda clase de daños producidos por servicios y obras públicas en sentido estricto, cualquiera que sea la modalidad de la prestación (directamente, o a través de entes filiales sometidos al derecho privado o por contratistas o concesionarios), la posición del sujeto dañado no tiene porqué ser recortado en su esfera garantizadora frente a aquellas actuaciones de titularidad administrativa en función de cuál sea la forma en que son llevadas a cabo y sin perjuicio, naturalmente, que el contratista y el concesionario puedan resultar también sujetos imputables».

\section{La STS de 25 de Octubre de 1996 indica que}

«El instrumento en que consiste la personificación jurídica puede resultar adecuado como método de organización para facilitar la eficacia en la actuación de 
las administraciones públicas, pero no permite a éstas exonerarse de sus respectivas responsabilidades frente a los particulares cuando las personas jurídicas creadas para atender a un sector de la actividad administrativa correspondiente a la administración matriz están en relación con ésta o con sus competencias, dependen de ella o se integran en su órbita de actuación. Este es el caso examinado, pues el Patronato Municipal de las Fiestas de Santa Tecla, como ha quedado acreditado en el proceso y se desprende de su misma denominación, tiene como objeto la organización de unas fiestas populares enraizadas en la tradición municipal de Sitges y por ende su actividad se relaciona con el ejercicio de sus competencias por el ayuntamiento, a quien corresponde velar por la seguridad y adecuada celebración de este tipo de actividades. Por otra parte, la intervención directa del ayuntamiento continúa existiendo a pesar de la actuación del patronato, pues es aquél el que autoriza la celebración de las fiestas, asumiendo con ello la responsabilidad de su buen desarrollo, y se encarga de las medidas adecuadas para que no se produzcan acontecimientos negativos que perjudiquen la seguridad de los participantes y de los vecinos del municipio. En suma, la existencia de una persona jurídica que colabora con las competencias del ayuntamiento primordialmente en el plano organizativo no puede constituir un elemento para privar a éste de su aptitud y, consiguientemente, de su deber de responder de las consecuencias derivadas de la actividad relacionada con el ejercicio de su competencia de mantenimiento de la seguridad con ocasión de las fiestas populares. Como en ello consiste la legitimación, tanto en el plano sustantivo (posición jurídica que obliga a un ente a hacerse cargo de una obligación existente) como procesal (posición en relación con una reclamación judicial que obliga a actuar como sujeto pasivo en el proceso), la primera alegación en la que la representación del ayuntamiento funda su defensa debe ser desestimada, de acuerdo con las apreciaciones de la sentencia impugnada. Un caso de responsabilidad patrimonial de la administración en relación con fiestas populares municipales organizadas por una entidad con personalidad jurídica incardinada en la organización municipal ha sido resuelta, partiendo de criterios análogos a los aquí afirmados, por la sentencia de esta Sala de 23 de febrero de $1995 \gg^{11}$.

\section{La STS de 9 de Mayo de 2005 (Sala de lo Civil) declara que}

«Los hechos probados que se imponen y han de ser respetados ponen de manifiesto que si bien la organización de la romería fue a cargo de la Hermandad de Santa Bárbara y tuvo lugar en finca particular, cuya propietaria había prestado la debida autorización y también fue demandada, resultando absuelta, no resulta el Ayuntamiento recurrente totalmente ajeno al trágico suceso ocurrido, al quedar demostrado que la mayoría de la gente que se integró en la romería había partido de la localidad de Villanueva, lo que obligaba al Ayuntamiento a haber adoptado las correspondientes medidas de control de tan importante movimiento de personas e incluso la ordenación del acto, y, al contrario, ninguna vigilancia llevó a cabo del lugar - ha de entenderse que tanto previamente como en el momento de celebrarse el acto festivo-, así como de vigilancia de la organización tan poco cuida-

\footnotetext{
${ }^{11}$ En similar sentido: SsTS de 17 de noviembre de 1998 y 19 de junio de 1998.
} 
dosa de la romería de referencia, llegando el Tribunal de Apelación a la conclusión decisoria de que no concurrieron circunstancias de fuerza mayor o de suceso fortuito, pudiendo el accidente haber sido previsto tanto por los organizadores del acto como por los controladores de su desarrollo, en este caso el Ayuntamiento.

Lo que se deja expuesto es determinante para no poder dejar por completo al margen del suceso a la parte recurrente, ya que su actuación se presenta claramente omisiva, pues si bien el Ayuntamiento no fue el organizador de la romería, no resulta totalmente extraño a la celebración y transcurso de la misma, ya que se trataba de un acto con afluencia máxima de gente, y como dice la STS de 11 de abril de 2000 existía el indudable deber del Ayuntamiento de velar por la seguridad del público presente en el acto, con la adopción de las medidas precisas de cercioramiento de que en el lugar de celebración no existían elementos susceptibles de causar daños a las personas y nada probó al respecto el recurrente. Es claro que se está ante un supuesto de culpa extracontractual previsto en el artículo 1902 del Código Civil».

\section{Igualmente, la STS de 24 de Mayo de 2005 sostiene que}

«A la vista de lo hasta aquí expuesto resulta claro para la Sala que la conducta de la Corporación Local implicada en el suceso no fue la adecuada puesto que se produjo el hecho que dio lugar a las lesiones sufridas por la recurrente. No puede excusarse el Ayuntamiento en el hecho de que la comitiva la organizaba una entidad privada, y no puede eximirle ese hecho de su responsabilidad en el suceso porque una vez que se hizo cargo de la custodia de la marcha lo fue con todas las consecuencias, y no a los meros efectos que pretende de cortar la circulación. Conocía o debía conocer las circunstancias que concurrían en el desfile, y que los participantes que componían la comparsa portaban los artefactos explosivos, uno de los cuales estalló y causó a la recurrente las lesiones que padeció. De este modo no ofrece duda que debió adoptar las medidas de seguridad adecuadas para garantizar la seguridad en el lugar público por el que discurría la comitiva para evitar un suceso como el que aconteció, y para ello debió evitar que las personas que contemplaban el paso del cortejo pudiesen ser lesionados por los petardos que era previsible que estallasen, como desgraciadamente ocurrió, obligándoles a mantener una distancia de seguridad de modo que al no hacerlo así se produjo el anormal funcionamiento del servicio en relación con la seguridad en lugares públicos. Con lo hasta aquí expuesto queda fuera de toda duda la responsabilidad patrimonial en que incurrió la Corporación Local demandada en la instancia fruto de la relación de causalidad existente entre las lesiones padecidas por la recurrente y la actividad desarrollada por la Corporación que resultó manifiestamente insuficiente para garantizar la seguridad de las personas que contemplaban el paso de la comitiva en la vía pública».

\section{C) Imputación de responsabilidad a la entidad matriz por levantamiento del velo de la personalidad jurídica del ente instrumental}

Desde una perspectiva general se ha sostenido que la creación de una persona jurídica es un privilegio que el ordenamiento confiere a quienes quie- 
ren satisfacer fines supraindividuales mediante la creación de un ente moral, al que se dota de realidad jurídica. Por ello, cuando los fines que se persiguen en la práctica no son merecedores de protección jurídica desaparece el presupuesto que formalmente legitimaba la atribución del privilegio y, en consecuencia, puede rasgarse el velo que encubría a una persona que ficticiamente se había vestido con los ropajes propios de una verdadera persona jurídica.

Constituye un hito en esta materia la Sentencia de la Sala primera del Tribunal Supremo de 28 de mayo de 1984, no por introducir una doctrina nueva, sino por condensarla y exponerla con rotundidad. Una sociedad anónima de titularidad privada sufre daños causados por una sociedad mercantil pública, gestora de servicio público. La empresa perjudicada presentó ante el Ayuntamiento, dentro de plazo, reclamación de resarcimiento de daños; después, y ante el silencio del Ayuntamiento, formuló reclamación ante la empresa municipal, pero esta segunda reclamación cuando ya había prescrito el plazo legal. La Sentencia comienza por declarar

"Que ya, desde el punto de vista civil y mercantil, la más autorizada doctrina, en el conflicto entre seguridad jurídica y justicia, valores hoy consagrados en la Constitución (artículos 1.1 y 9.3), se ha decidido prudencialmente, y según casos y circunstancias, por aplicar por vía de equidad y acogimiento del principio de buena fe (artículo 7.1 del Código Civil), la tesis y práctica de penetrar en el «substratum» personal de las entidades o sociedades, a las que la ley confiere personalidad jurídica propia, con el fin de evitar que al socaire de esa ficción o forma legal (de respeto obligado, por supuesto) se puedan perjudicar ya intereses privados o públicos o bien ser utilizada como camino de fraude (artículo 6.4 del Código Civil), admitiéndose la posibilidad de que los jueces puedan penetrar («levantar el velo jurídico») en el interior de esas personas cuando sea preciso para evitar el abuso de esa independencia (artículo 7.2 del Código Civil) en daño ajeno o de «los derechos de los demás» (artículo 10 de la Constitución) o contra interés de los socios, es decir, de un mal uso de la personalidad, de un «ejercicio antisocial» de su derecho (artículo 7.2 del Código Civil)».

Las SsTS de 4 de junio de 1992 y 25 de octubre de 1996, indicarán que

«...es cierto que nuestro ordenamiento jurídico positivo y según las concepciones teóricas del Derecho administrativo el Ayuntamiento tiene potestad suficiente para crear fundaciones públicas del servicio, análogas a los organismos autónomos estatales, con personalidad y patrimonio propio. Sin embargo, es de tener en cuenta la corriente jurisprudencial mantenida por esta Sala en sentencias recientes en el sentido de que la personificación como instrumento de la potestad organizatoria de la Administración no puede utilizarse por los entes públicos para eludir el cumplimiento de sus obligaciones y derechos que consagra el ordenamiento jurídico». 


\section{LA RESPONSABILIDAD PATRIMONIAL DE LOS ENTES INSTRUMENTALES DE LA ADMINISTRACIÓN}

Y así la doctrina del levantamiento del velo de la personalidad jurídica ${ }^{12}$ permite entrar en el substrato de las personas jurídicas a fin de evitar un mal uso de la personalidad, en un ejercicio antisocial del Derecho, o en perjuicio de tercero,

«...también en el ámbito del Derecho administrativo, cuando se habla de los entes públicos o de gestión, a los que se reviste de una forma jurídica perteneciente al derecho privado...no se hace sino utilizar una técnica ofrecida por ese derecho de modo instrumental, del uso de un procedimiento en el que la sociedad aparece como una simple forma para encubrir la creación de un ente filial puro y simple, externamente regido por el Derecho privado, pero en realidad - internamente-de la pertenencia de la Administración...circunstancia más que suficiente para no considerar tercero o extraño al Ayuntamiento con respecto a la sociedad municipal demandada...» (STS, Sala $1^{a}$, de 28 de mayo de 1984, antes citada).

En consecuencia, y como dirá la STS de 9 de junio de 1988, «es necesario levantar el velo de la personalidad jurídica para apreciar la auténti-
ca relación que une al Ayuntamiento con las fundaciones públicas que de él depen-
den, que es una relación fiduciaria, en virtud de la que el ente matriz -Ayuntamien-
to de Barcelona - confía al Patronato la realización de una finalidad concreta:
guardería infantil. La personalidad de la fundación, por más que sea un instrumen-
to útil de cara a facilitar una más ágil gestión no puede hacer perder de vista el
carácter de simple órgano que en las relaciones internas tiene aquella».

Para la STS de 12 de junio de 1984 «es este principio de la buena fe el que debe impedir que la Administración trate de crear una situación de confusionismo, valiéndose de la circunstancia de la coincidencia de una misma persona en los dos cargos de Presidente del patronato municipal y de Alcalde, para llegar a un resultado que implica un fraude de ley, una frustración de los legítimos derechos de la empresa recurrente», ya que «la personalidad jurídica que haya podido reconocerse a tal Patronato no pasa de ser un recurso técnico-jurídico, para agilizar y facilitar su gestión específica, pero sin que ello venga a representar, sobre todo en la práctica, que ese ente pueda ser considerado como un auténtico penitus extransi»; añadiendo que «el principio de eficacia administrativa no puede utilizarse para sortear las exigencias propias de un Estado de Derecho».

\footnotetext{
${ }^{12}$ Boletín del Ilustre Colegio de Abogados de Madrid: El levantamiento del velo, núm. 22/2002. SANTIAGo ORTIZ VAAMONDE: El levantamiento del velo en el derecho administrativo, La Ley, Madrid, 2004.
} 